\section{Sleepless in Seattle}

\author{
A new superconductor had physicists burning \\ the midnight oil at their get together last week. \\ Sarah Tomlin joined in the fun.
}

$\mathrm{T}$ here were some tired eyes at the meeting of the American Physical Society (APS), held last week in Seattle. A new superconductor had physicists acting like teenagers, cramming lecture theatres to see the stars of the show and staying up until the early hours to discuss the latest gossip. The session was immediately christened 'Woodstock West' - a nod to the original 'Woodstock of Physics', the 1987 APS session on the first high-temperature superconductors, which are based on copper oxide.

Centre stage this time around was magnesium diboride $\left(\mathrm{MgB}_{2}\right)$, a new superconductor that burst onto the scene this January. It was unveiled at a conference in Japan, when Jun Akimitsu of Aoyama Gakuin University in Tokyo revealed that $\mathrm{MgB}_{2}$ loses all its electrical resistance and superconducts at temperatures of up to $39 \mathrm{~K}$ (ref. 1), twice the previous record for a stable metallic superconductor. The compound is also cheap and easy to make. "It's your fantasy material," says Paul Canfield, leader of an Iowa State University group, who has already made superconducting wires from the compound ${ }^{2}$.

The earliest superconductors were all metallic, but needed cumbersome and expensive equipment to cool them to a few degrees above absolute zero before they lost their electrical resistance. That all changed in 1986 after the discovery of high-temperature

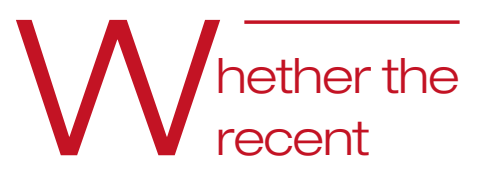

excitement translates into real applications remains to be seen.

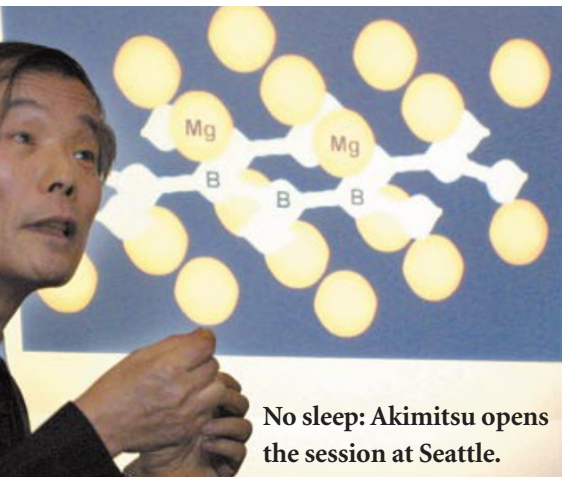

NATURE |VOL 410|22 MARCH 2001 |www.nature.com superconductivity in the copper oxides. By the time of the original physics Woodstock, materials such as yttrium barium copper oxide had been found to superconduct at up to $90 \mathrm{~K}$. Simple metallic superconductors were almost forgotten by those searching for superconductivity at higher temperatures.

Now they are definitely back in fashion. Once news of $\mathrm{MgB}_{2}$ 's superconducting properties was out, a frenzy of e-mails and phone conversations sent the story around the physics world, culminating in last week's hastily arranged meeting.

\section{Instant celebrity}

As the word spread, physicists switched their research to concentrate on $\mathrm{MgB}_{2}$. "We've been working 16 hours a day, seven days a week on this," says Canfield. "It's been damn exciting fun." The latest findings were shared over the Internet via the Los Alamos archive (http://www.arxiv.org), a repository of preprints. Back in 1987 it was the fax machine that powered the spread of results. This time, said Princeton University's Bob Cava at the meeting, "the excitement was fanned by instantaneous communication".

If the past two months were a sprint, the 12 March evening session was a marathon. Midnight came and went before the 80 speakers had finished. More than 1,000 physicists crammed into the room, with yet more outside, to hear Akimitsu start the talks. Subsequent speakers were allowed only two minutes, strictly enforced, with one minute for questions.

Several groups described how $\mathrm{MgB}_{2}$ could be made into wires and thin films the first steps towards practical devices. The Iowa State researchers have found a simple way to make superconducting wires: they expose commercial boron fibres to magnesium vapour at $950 \mathrm{~K}$. Canfield believes the same technique could produce superconducting magnets or other devices.

From the evidence presented at Seattle, it seems that $\mathrm{MgB}_{2}$ behaves like a conventional low-temperature metallic superconductor - except, of course, it works at a much higher temperature. This came as a surprise to most physicists, who have struggled to work out what is going on in the copper oxides, which appear to follow a different, and largely mysterious, mechanism.

But if $\mathrm{MgB}_{2}$ is a conventional supercon-

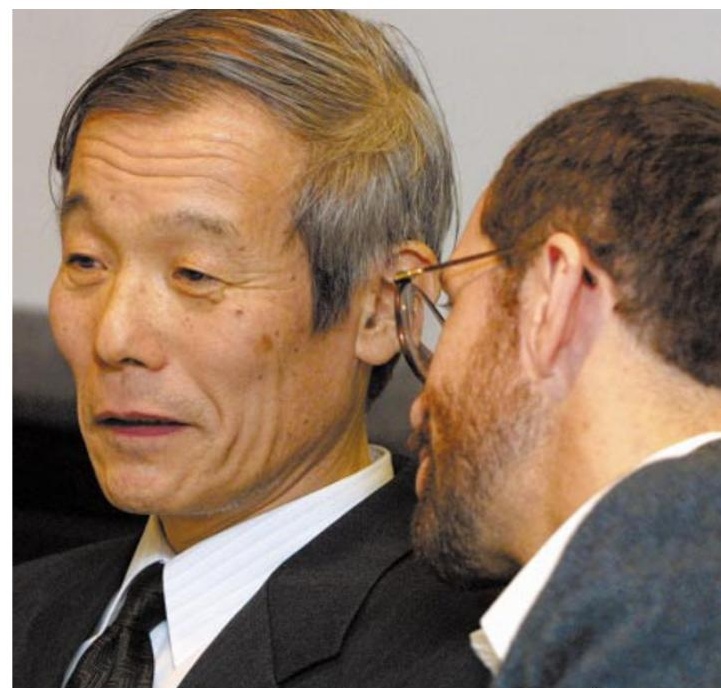

Hot stuff: Jun Akimitsu (left) stunned physicists when he revealed that magnesium diboride superconducts at surprisingly high temperatures.

ductor, what is it that makes $\mathrm{MgB}_{2}$ conduct at higher temperatures? Cracking that problem could lead to new superconductors. "If we can understand what makes this structure survive at these temperatures, then it might point the way to other materials," says Canfield.

So far, attempts to improve $\mathrm{MgB}_{2}$ 's performance have been unsuccessful. For example, a tried and trusted method for improving the high-temperature copper oxide superconductors is to change their composition by chemical substitution. But when Cava's group tried to replace some of the magnesium in $\mathrm{MgB}_{2}$ with aluminium, the superconductivity was destroyed ${ }^{3}$. It is still early days, and instead of substitution, adding a third element to $\mathrm{MgB}_{2}$ may open up more possibilities.

The next step is to use $\mathrm{MgB}_{2}$ to make practical devices. Researchers are cautious when talking about potential applications, in part because many of the proposed uses for hightemperature superconductivity failed to materialize. Copper oxide superconductors are hard to engineer into wires, so standard metallic superconductors such as niobium-tin and niobium-titanium are still widely used for superconducting applications such as magnets for magnetic resonance imaging instruments.

Even though $\mathrm{MgB}_{2}$ has a moderate superconducting temperature, its low cost may make it a viable alternative to the copper oxide superconductors. Whether the excitement of the past few weeks translates into real applications remains to be seen. But the tired physicists heading back to their labs after their marathon session in Seattle are on the case.

Sarah Tomlin is associate News \& Views editor at Nature.

1. Nagamatsu, J. et al. Nature 410, 63-64 (2001)

2. Canfield, P. C. et al. Phys. Rev. Lett. 86, 2423-2426 (2001).

3. Slusky, J. S. et al. Nature 410, 343-345 (2001). 